Revista lus et Praxis, Año 24, No 3, 2018, pp. 525 - 552

ISSN 0717 - 2877

Universidad de Talca - Facultad de Ciencias Jurídicas y Sociales

La precariedad del contencioso ambiental

Pablo Méndez

Trabajo recibido el 2 de agosto de 2017 y aprobado el 9 de agosto de 2018

\title{
La precariedad del contencioso ambiental
}

\section{THE ENVIRONMENTAL JUDICIAL REVIEW PROCEDURE'S PRECARIOUSNESS}

\section{PABlo MÉndez}

RESUMEN

Este trabajo sostiene que el contencioso-administrativo de la Ley $N^{\circ} 20.600$ es un procedimiento "sumarísimo", cuya precariedad genera dos consecuencias negativas: limita tanto el contradictorio de las partes en el juicio como las facultades revisoras del tribunal ambiental. Esto último, pese a ser un tribunal altamente especializado.

\section{ABSTRACT}

This Article contends that the judicial review procedure established in Law $N^{\circ} 20.600$ is a summary trial, which precariousness generates two negative consequences. First, it limits the adversarial system. Second, it limits the environmental court's power to review, even though it is a highly-specialized court.

\section{PalABRAS CLAVE}

Tribunales Ambientales, contencioso-administrativo, justicia administrativa, revisión judicial

KEY WORDS

Environmental courts, review of agency actions, administrative justice, judicial review

\section{Introducción}

La Ley $N^{0} 20.600$, de 2012, junto con crear tribunales ambientales como tribunales especializados, también creó un procedimiento contencioso-administrativo para el conocimiento de la impugnación judicial de actos de contenido ambiental dictados por los organismos de la Administración del Estado. Hasta la fecha, este procedimiento ha sido utilizado por los particulares, la mayor

\footnotetext{
* Licenciado en Derecho, Universidad de Valparaíso (Chile). Master en Derecho, New York University(Estados Unidos). Profesor del Departamento de Derecho Económico y Tributario, Escuela de Derecho, Universidad de Valparaíso. Dirección postal: Errázuriz 2120, Valparaíso. Dirección electrónica: pmo231@nyu.edu. Agradezco los comentarios de Jorge Cabrera y Pablo Tejada a un borrador previo de este trabajo.

Una versión temprana y distinta de los argumentos aquí expuestos, fue presentada en la Comisión de Derecho Administrativo de las XLV Jornadas de Derecho Público (23 de octubre de 2015) en la Escuela de Derecho de la Universidad de Valparaíso. Estoy en deuda con los profesores Drs. Jorge Bermúdez, Carlos Dorn, Ramón Domínguez y Juan Carlos Ferrada con sus interesantes comentarios a aquella versión.
} 
parte de las veces, en contra de la Superintendencia del Medio Ambiente y del Servicio de Evaluación Ambiental'

En este escenario, una pregunta importante es qué tan eficientes son las reglas de procedimiento establecidas en dicha ley, al ser analizadas a la luz de (i) los derechos de las partes procesales y (ii) las características de los tribunales ambientales como tribunales contencioso-administrativos especializados. La pregunta es pertinente pues las reglas de procedimiento no solo constituyen una garantía para los sujetos administrados en su derecho al contenciosoadministrativo $^{2}$. Ellas, además, influyen en la forma en que el juez se impone del asunto que las partes han sometido a su conocimiento. Bajo este prisma, dichas reglas importan porque impactan en la manera en que el órgano jurisdiccional ejerce su función.

Este trabajo viene a llenar un actual vacío en la literatura académica sobre la revisión judicial en materia administrativa especializada en nuestro país. Muchos trabajos se han enfocado en el contencioso-administrativo en términos generales ${ }^{3}$; otros tantos han puesto la atención en las características del órgano revisor ${ }^{4}$. Algunos se han focalizado en la relación existente entre las características institucionales de dichos órganos y sus facultades revisoras ${ }^{5}$. Sin embargo, actualmente no hay trabajo alguno que se encargue de analizar las normas procesales del contencioso-administrativo en relación a las partes procesales y a la labor revisora que realiza un órgano jurisdiccional de esta naturaleza.

Como se expondrá, las reglas de procedimiento de la Ley $N^{0} 20.600$ son inadecuadas e ineficientes como contencioso-administrativo. Por una parte; (i) ellas consagran una tramitación sumarísima -similar a la existente para la acción constitucional de protección-que carece de un contradictorio adecuado entre las partes, impide la depuración de vicios procesales previo a conocer el fondo del asunto, opera sobre la idea de que el órgano revisor realiza una

\footnotetext{
1 Se habían presentado en total doscientas treinta y dos reclamaciones ante los tres tribunales ambientales al 31 de diciembre de 2017. La mayoría de ellas se encuentran dirigidas contra la Superintendencia del Medio Ambiente; mientras que, en otro menor número de casos, el organismo reclamado es el Servicio de Evaluación Ambiental. Tribunal Ambiental de Santiago (2018); Tribunal Ambiental de Valdivia (2018), y Tribunal Ambiental de Antofagasta (2018).

2 Fue Lon Fuller quien sostuvo que la adjudicación descansa sobre la esencia de otorgar a las partes una particular forma de participación en la decisión judicial a través de presentar pruebas y argumentos razonados para una decisión en su favor. Fuller (1978), p. 364.

3 Por ejemplo, Bordalí y Ferrada (2008).

4 A modo meramente ejemplar, Boettiger (2015).

5 Por ejemplo, TAPIA y Cordero (2015).
} 
mera revisión del expediente administrativo y restringe los Medios probatorios en forma drástica. Por otra parte, (ii) estas reglas son incongruentes con la forma en que los tribunales ambientales ejercen sus facultades revisoras. Pese a que los tribunales ambientales cuentan con incentivos altos para no ser deferentes con las decisiones adoptadas por la Administración ambiental y ejercer una revisión amplia, aquellas reglas operan como obstáculos en el ejercicio de la función revisora por parte de los tribunales ambientales.

Para responder la pregunta que motiva el presente trabajo se asumirá la siguiente estructura. En la sección 1 se expone el problema existente bajo la antigua jurisdicción ambiental, esto es, aquella existente hasta antes de la Ley $N^{\circ}$ 20.600. Ello permite entender las razones que motivaron la promulgación de esta ley y la consecuente creación de los tribunales ambientales en nuestro país. En la sección 2 se analiza la solución ofrecida por el legislador a este problema a través de la Ley No 20.600. Esta consistió, en pocas palabras, (i) en la creación de tribunales contencioso-administrativos altamente especializados y (ii) en la instauración de reglas procesales virtualmente idénticas a las establecidas para la tramitación de la acción constitucional de protección, que era el proceso de impugnación por antonomasia que utilizaban los opositores a los grandes proyectos de inversión en nuestro país, hasta esa fecha. Las dos secciones siguientes buscan detallar y analizar las consecuencias generadas por dichas reglas procedimentales. Primero, en la sección 3 se demuestra que dichas reglas limitan la posibilidad que tienen las partes para generar un contradictorio adecuado ante los tribunales ambientales. Segundo, en la sección 4 se comprueba que aquellas reglas operan como obstáculos para que los tribunales puedan ejercer sus facultades revisoras de manera eficiente, lo cual es incongruente con los motivos institucionales que fundamentaron su implementación. La sección 5 contiene algunas conclusiones a las preguntas que han dado origen a este artículo.

\section{El problema detrás de la antigua jurisdicción ambiental}

\subsection{El antiguo modelo de impugnaciones en materia ambiental}

Como es sabido, hoy en día las competencias contencioso-administrativas de los tribunales ambientales se encuentran relacionadas, en síntesis, con la impugnación de tres clases de actuaciones administrativas ${ }^{6}$ : (i) actos dictados en el contexto del Sistema de Evaluación de Impacto Ambiental ("SEIA"); (ii) actos dictados por la Superintendencia del Medio Ambiente, esto es, fundamentalmente, resoluciones dictadas en el marco de un procedimiento

${ }^{6}$ Art. 17, Ley № 20.600, de 2012. 
sancionatorio, y; (iii) ciertas normas ambientales de aplicación general ${ }^{7}$. Lo que hizo a este respecto la Ley $N^{0} 20.600$ fue unificar en los tres tribunales ambientales todas las impugnaciones en contra de actos administrativos de contenido ambiental que hasta ese momento existían en nuestro país ${ }^{8}$.

Hasta antes de la Ley $N^{\circ}$ 20.600, el modelo de impugnación asociado a dichos actos administrativos era el siguiente: en el caso de las resoluciones de calificación ambiental dictadas en el Sistema de Evaluación de Impacto Ambiental, se concedía acción de reclamación al titular del proyecto contra el acto administrativo que rechazara la Declaración o el Estudio de Impacto Ambiental, o bien, que impusiera condiciones o exigencias sobre el último ${ }^{9}$. Esta acción operaba tras el agotamiento de la vía administrativa. Terceros que formulaban observaciones al Estudio solo contaban con una reclamación administrativa, pero que en ningún caso llegaba a judicialización ${ }^{10}$. Es probable que, por ello, el mecanismo de impugnación (o contenciosoadministrativo) por excelencia que usaron estos terceros durante esta época, fue la acción constitucional de protección ${ }^{11}$.

En el caso de sanciones, la situación era un tanto distinta. Hasta antes de lo que se conoció como la "Nueva Institucionalidad Ambiental" de 2010, las facultades sancionatorias respecto al incumplimiento de resoluciones de calificación ambiental estaban radicadas en las Comisiones Regionales ("Coremas") o en la Comisión Nacional del Medio Ambiente ("Conama") ${ }^{12}$.

\footnotetext{
7 Por "normas ambientales de aplicación general" me refiero a las Normas de Calidad Ambiental, Normas de Emisión, Declaraciones de Zonas Latentes y Saturadas, y Planes de Prevención y Descontaminación.

${ }^{8}$ Hay un par de matices al respecto, pero ellos no son relevantes para el argumento de este trabajo. La Ley N 20.600 también incorporó dos acciones nuevas: la acción de impugnación de actos administrativos que dicten Ministerio o servicios públicos para la ejecución o implementación de las normas ambientales de aplicación general (art. $17 \mathrm{~N}^{0} 7$ ); y lo que se ha denominado como acción de impugnación de carácter general, destinada a la nulidad de cualquier acto administrativo de contenido ambiental tras el agotamiento de la vía administrativa (art. 17 No 8). Al respecto, Bermúdez (2014), p. 538; FerRADA (2015), pp. 310-311.

9 Art. 20, Ley № 19.300 (antes de la Ley No 20.417), de 1994.

10 Art. 29, Ley No 19.300 (antes de la Ley No 20.417), de 1994.

11 Sobre el panorama de la acción constitucional de protección antes de la Ley № 20.600, GALINDO (2001); CORDERO (2012).

12 Por "Nueva Institucionalidad Ambiental" se conoce a aquella creada e implementada por la Ley $N^{0}$ 20.417, de 2010, que reformó el sistema administrativo ambiental existente hasta dicho momento. Esta Ley creó (i) el Ministerio del Medio Ambiente, a cargo de la definición de políticas y normas de regulación ambiental; (ii) el Servicio de Evaluación Ambiental, encargado de la administración del Sistema de Evaluación de Impacto Ambiental y el otorgamiento de autorizaciones ambientales; y (iii) la Superintendencia del Medio Ambiente, con competencia de fiscalización y sanción respecto de los
} 
Las resoluciones sancionatorias eran reclamables ante la justicia ordinaria y el juez contaba con facultades para mantener, modificar o revocar la sanción impuesta por la administración ${ }^{13-14}$. Por último, las normas ambientales de aplicación general eran directamente reclamables también ante la justicia ordinaria por cualquier persona, siempre que acreditare un perjuicio ${ }^{15}$.

En todos estos casos, el juez competente era el juez de letras en lo civil. Las acciones se tramitaban conforme al procedimiento sumario del Código de Procedimiento Civil y todos los Medios de prueba eran admisibles, los que eran apreciados conforme a la sana crítica. La sentencia definitiva era susceptible de recurso de apelación ${ }^{16}$.

\subsection{El antecedente de los tribunales ambientales}

Como consecuencia del modelo expuesto, el acceso a la justicia ambiental durante la década de los '90 y en los 2000 en nuestro país, se fue dando con no pocas problemáticas. Este acceso no solo careció de tribunales especializados que se hicieran cargo de los conflictos ambientales; sino que también se fue materializando a través de herramientas jurídicas deficientes, utilizadas más por una necesidad de aplicación práctica por parte de los diversos operadores, que por pertinencia jurídica. Tal como fue mencionado en la sección anterior, esto se manifestó de forma evidente a través de la interposición de acciones constitucionales de protección en contra de las resoluciones de calificación ambiental favorables dictadas en el marco del SEIA ${ }^{17}$. Esto, con todo, no respondió sino a la regla general en nuestro sistema, en donde esta acción se transformó en un frecuente sucedáneo de contencioso-administrativo, pro-

instrumentos de gestión ambiental. Sobre esto, Bermúdez (2014), pp. 80-103; Guiloff (2011), pp. 231 242; Boettiger (2010), pp. 429-454 y Hervé et al. (2010).

13 Art. 64, Ley $N^{0} 19.300$ (antes de la Ley $N^{0}$ 20.417), de 1994. En este caso, las facultades de fiscalización correspondían a los organismos de la Administración del Estado que habían participado de la evaluación ambiental del proyecto o actividad ingresado al SEIA. Sobre esto, BERMúdEZ (2014), p. 412.

14 Este panorama no se vio alterado con la Ley $\mathrm{N}^{0} 20.473$, que estableció un régimen intermedio mientras la Superintendencia del Medio Ambiente comenzaba a operar en funciones. Tras la supresión de las Coremas y Conama (con la Ley No 20.417 de 2010), la Ley No 20.473, de 2010, en su artículo único, entregó a la Comisión de Evaluación Ambiental las facultades sancionatorias respecto del incumplimiento de resoluciones de calificación ambiental, hasta que la Superintendencia del Medio Ambiente entrara en funciones. Para lo que aquí interesa, la Ley № 20.473, de 2010, replicó el contencioso administrativo existente hasta la fecha en la Ley $N^{\circ}$ 19.300, de 1994.

15 Art. 50, Ley No 19.300 (antes de la Ley No 20.417), de 1994.

16 Arts. 60-62, Ley No 19.300 (antes de la Ley No 20.417), de 1994.

17 Una exposición del panorama durante los primeros años (1996-2000) en GaLINDO (2001). 
bablemente debido a su desformalización, la rapidez en su tramitación y las amplias facultades con que cuenta el juez para dictar prácticamente cualquier medida de protección ${ }^{18}$.

Esta situación fue detectada por la OCDE (Organización de Cooperación y Desarrollo Económico) y descrita en su Primer Informe de 2005 sobre la Evaluación del Desempeño Ambiental de Chile:

"Los tribunales tratan un gran número de casos ambientales, lo cual pone de relieve que la población ejerce su derecho a acudir a los tribunales, pero también que muchas controversias ambientales no se resuelven mediante los procedimientos administrativos. Más aún, el sistema judicial carece de la capacidad para tratar debidamente una buena cantidad de asuntos ambientales, por ejemplo, a la hora de obtener pruebas o estimar el daño ambiental y calcular el valor de las indemnizaciones. No hay defensor del pueblo ni ninguna otra institución independiente que actúe como último recurso para garantizar la defensa de los derechos ciudadanos"19.

Durante esta época, una parte relevante de la doctrina en nuestro país criticó la utilización del recurso de protección como un contencioso-administrativo. Así, se cuestionó constantemente su carácter simple y desformalizado que le impide al juez conocer temas complejos de orden técnico, así como la inexistencia de recursos jurisdiccionales, salvo el de apelación ante la Corte Suprema ${ }^{20}$. Dichas críticas alcanzaron, desde luego, a la utilización de esta acción en el ámbito del Derecho ambiental ${ }^{21}$.

En este contexto, el golpe de gracia lo dio la Corte Suprema al dictar sentencia en el Caso Campiche en junio de 2009, confirmando el fallo de la Corte de Apelaciones de Valparaíso que declaraba la nulidad de la resolución de calificación ambiental que autorizaba el proyecto adoleciendo un error en su emplazamiento ${ }^{22}$. A partir de entonces, la Tercera Sala de la Corte Suprema se apartó de la doctrina judicial clásica de deferencia hacia los actos de la administración ambiental para comenzar a examinar y pronunciarse sobre una serie de aspectos asociados a la "Nueva Institucionalidad Ambiental" y, particularmente,

\footnotetext{
18 Bordalí y Ferrada (2008), pp. 209 y ss.; Bermúdez (2011), pp. 458 y ss.

19 Organización de Cooperación y Desarrollo Económicos (2005), p. 197.

20 Pierry (1977), p. 177, señalando que "el recurso de protección no sustituye a lo contencioso administrativo". En el mismo sentido, Pierry (1991), Ferrada et al. (2003), Bordalí y Ferrada (2008), pp. 227 y ss.

21 Galindo (2006).

${ }^{22}$ Corte Suprema, rol № 1219-2009, de 22 de junio de 2009. Un comentario de esta sentencia y sus efectos en Guiloff (2010).
} 
al Sistema de Evaluación de Impacto Ambiental ${ }^{23}$. Durante esta época, algunos incluso criticaron la forma en que los tribunales superiores de justicia estaban resolviendo los casos ambientales, señalando que ellos, como cortes generalistas, no estaban preparadas para resolver asuntos técnicos como los ambientales ${ }^{24}$.

\section{La solución: la creación de tribunales ambientales como tribunales contencioso-administrativo especializados}

En este contexto, el origen de los tribunales ambientales en nuestro país puede ser rastreado hasta una fecha específica: el 26 de octubre de $2009^{25}$. Aquel día, el Ejecutivo -representado en dicha ocasión por los Ministros de Medio Ambiente y Hacienda- y los Senadores de los partidos de la Concertación Democrática, de la Coalición por el Cambio e independientes, suscribieron un Protocolo de Acuerdo en el marco de la tramitación constitucional del Proyecto de Ley que creaba la Nueva Institucionalidad Ambiental (Boletín No 5917-12). En muchos sectores políticos existía la idea de que la Superintendencia del Medio Ambiente, tal como se encontraba concebida en dicho Proyecto, contaría con facultades de fiscalización y sanción exorbitantes, de modo que se hacía necesario un tribunal especializado que estuviera a la altura -desde un punto de vista técnico- y pudiera controlar a dicho órgano administrativo. Por otra parte, también existía incomodidad en cómo las cortes generalistas estaban resolviendo los recursos de protección en materia ambiental, según se ha visto.

Así, a través del Protocolo mencionado, se garantizó el respaldo parlamentario de las respectivas bancadas para las aprobaciones necesarias, comprometiéndose una rápida tramitación para el Proyecto de Ley en cuestión. Como moneda de cambio, el Ejecutivo se obligó a ingresar un proyecto de ley para crear un Tribunal Ambiental. Dicho Tribunal contaría con competencias relativas al contencioso administrativo ambiental y de revisión sobre los actos de la SMA, incluyendo algunas de control previo sobre ciertos actos que dictare este organismo.

Con algunos cambios durante su tramitación, en enero de 2012 fue aprobado el Proyecto de Ley de Tribunales Ambientales con el número 20.600. Esta ley, según se demostrará a continuación, (i) creó tres tribunales ambientales como tribunales especiales de competencia exclusiva y excluyente para la revisión de actos administrativos, conformados por miembros especialistas

\footnotetext{
${ }^{23}$ Un panorama general en CORDERO (2012).

${ }^{24}$ Sobre esto, CORDERO (2012).

25 Para una acabada relación acerca del origen de la Ley № 20.600: Centro de Derecho Ambiental (2012) y Poklepovic (2012). Recientemente, MéNdez (2017), pp. 33-49.
} 
y no sujetos preferentemente a las cortes generalistas de nuestro país (i.e., las Cortes de Apelaciones) y; (ii) consagró un contencioso-administrativo con reglas virtualmente idénticas al recurso de protección. Esto es lo que se analizará a continuación.

\subsection{Los tribunales ambientales como tribunales contencioso-administrativo especializados}

La especialización de un tribunal que revisa los actos de la Administración del Estado no es un concepto binario ${ }^{26}$. Lo correcto no es diferenciar a los tribunales especializados de aquellos que no lo son; lo que corresponde es hablar de tribunales que son "más especializados que otros". La especialización de un tribunal es una característica gradual que opera en base a tres criterios: su competencia, su composición y la relación que eventualmente tenga con las cortes generalistas ${ }^{27}$.

\subsubsection{Un tribunal con competencias exclusivas y excluyentes...}

Hay dos criterios en la competencia de un tribunal que pueden ser relevantes a la hora de estimar su grado de especialización: la exclusividad y la especificidad. Con base en la exclusividad, es posible distinguir un tribunal que tiene autoridad para conocer de todos y cada uno de los casos de un cierto tipo (excluyendo por tanto a cualquier otro), de un tribunal que, teniendo competencia, no impide a otros conocer del mismo asunto. Por otra parte, según la especificidad en su competencia, los tribunales pueden conocer solo de un tipo particular de casos (i.e., medioambiente, libre competencia, tributos) o bien conocer de todos los casos en general (o tribunales "generalistas") ${ }^{28}$.

\footnotetext{
26 Uso la expresión "especialización" en su sentido natural y obvio, como algo limitado "a un uso o fin determinado" (Definición de "especializar", RAE, 23ª edición). No debe confundirse este concepto con la clasificación tradicional que se ha hecho en nuestro Derecho entre tribunales ordinarios y especiales con fundamento en el artículo $5^{\circ}$ del Código Orgánico de Tribunales. Así, se ha dicho que los tribunales ordinarios son "aquellos establecidos en el inciso $2^{\circ}$ del artículo $5^{\circ}$ y en los Títulos III, IV, V y VI del Código Orgánico de Tribunales y que Ilevan consigo la idea de subordinación del inferior con respecto al superior" CASARINO (2014), p. 44; mientras que los especiales son los "establecidos por la ley para juzgar a determinadas materias, las que, por circunstancias particulares, gozan de este privilegio". CASARINO (2014), p. 46. Sin perjuicio de ello, esta clasificación normativa sí impacta en la especialización del tribunal, según se demostrará en las líneas que siguen.

27 Sobre esto, Revesz (1990), pp. 1121-1137, a quien sigo de cerca en la utilización de estos criterios. También CANE (2009), pp. 91-101; 114-124 y 128-137.

28 Esta variable ha sido tomada clásicamente para distinguir a tribunales de jurisdicción común y de jurisdicción especial. Al respecto, CASARINO (2014), pp. 48-51.
} 
Los tribunales ambientales cuentan con una competencia específica. Por mandato legal expreso, los tribunales ambientales fueron creados para conocer solo de aquellos asuntos que cuenten con una naturaleza específica: las "controversias medioambientales de su competencia" ${ }^{29}$. Para ello, los tribunales ambientales cuentan con competencias contencioso-administrativas relativas a acciones de reclamación en contra de determinados actos administrativos de contenido ambiental ${ }^{30}$. Así, bajo la Nueva Institucionalidad Ambiental y la Ley $N^{\circ} 20.600$, estos tribunales pasaron a conocer y resolver las cuestiones ambientales en nuestro sistema legal.

Por otra parte, la competencia que detentan los tribunales ambientales es, hoy por hoy, preferentemente excluyente. Así, lo ha confirmado en el último tiempo la Corte Suprema en diversas sentencias dictadas a propósito de acciones constitucionales de protección que han buscado la invalidación de resoluciones de calificación ambiental. Nuestra máxima Corte ha señalado en estos casos que tras la dictación de la Ley No 20.600 y la implementación de los tribunales ambientales, "[e]s ante esa jurisdicción especial y por esa vía entonces donde debe instarse por la invalidación de una resolución de calificación ambiental" 31 , estando así, por regla general, imposibilitada la interposición de recursos de protección para dicho fin ${ }^{32}$.

\subsection{2. ...conformado por jueces especializados...}

Un segundo elemento que influye en el grado de especialización que puede tener un tribunal es, desde luego, su composición. La cuestión pasa por determinar si el tribunal estará compuesto por jueces especialistas en un área determinada o por jueces generalistas sin formación o experiencia en un ámbito del Derecho. En nuestro país, usualmente la instauración de tribunales

\footnotetext{
29 Art. $1^{\circ}$, Ley $\mathrm{N}^{\circ} 20.600$, de 2012.

${ }^{30}$ Art. $17 \mathrm{~N}^{\mathrm{o}}$ s. 1, 3, 5, 6, 7 y 8, Ley $\mathrm{N}^{\mathrm{o}}$ 20.600, de 2012. Sin perjuicio de ello, los tribunales ambientales también ejercen un control preventivo sobre ciertos actos administrativos dictados por la Superintendencia del Medio Ambiente (art. $17 \mathrm{~N}^{\circ}$ 4) y conocen de acciones por daño ambiental (art. $17 \mathrm{~N}^{\circ} 2$ ).

31 Corte Suprema, rol № 2892-2014, de 29 de abril de 2014, cons. $7^{\circ}$. En igual sentido, Corte Suprema, rol No 8774-2014, de 25 de agosto 2014, cons. $4^{\circ}$.

32 Esta regla general no ha impedido que la Corte Suprema acoja excepcionalmente recursos de protección en contra de actos administrativos ambientales cuando en su concepto es necesaria una cautela urgente. Por ejemplo, Corte Suprema, rol No 11299-2014, de 29 de abril de 2014.
} 
especiales ha derivado en la integración de estos con jueces especialistas en las materias de competencia del tribunal respectivo ${ }^{33}$.

Esto ha ocurrido también en el caso de los tribunales ambientales. Ellos se encuentran integrados por tres ministros, dos de los cuales deben tener título de abogado y con cierto tiempo de experiencia comprobable en materias de Derecho Administrativo o Ambiental; mientras que el tercero deberá ser un licenciado en ciencias con especialización en ciencias medioambientales ${ }^{34}$. A ello debe agregarse que estos tribunales cuentan, dentro de su personal de planta, con profesionales del ámbito económico y del ámbito de las ciencias ${ }^{35}$. En doctrina hay varias razones por las cuales se ha defendido la necesidad de especialización de los jueces en materias ambientales ${ }^{36}$. Ello no ha impedido algunas críticas dentro de nuestra doctrina nacional al sistema de nombramiento de ministros para estos tribunales ${ }^{37}$.

Consta en la historia de la Ley № 20.600 que con este modelo se buscó seguir uno similar al del Tribunal de Defensa de la Libre Competencia, conformado por jueces letrados y por jueces que, no invistiendo tal calidad, contaren con una "especialización que contribuye a una razonable y acabada decisión de asuntos ambientales" ${ }^{\prime 38}$. Consecuentemente, en nuestro sistema legal es bastante claro que fue el alto contenido técnico envuelto en las materias ambientales lo que justificó un tribunal especializado y de integración mixta ${ }^{39}$.

33 Es lo que ha ocurrido, por ejemplo, con el Tribunal de Contratación Pública (art. 22, inc. $3^{\circ}$, Ley No 19.886, de 2003), el Tribunal de Defensa de la Libre Competencia (art. 6º , Ley № 19.911, de 2003) y los Tribunales Tributarios y Aduaneros (art. 6º , Ley No 20.322, de 2009).

${ }^{34}$ Art. 2 ${ }^{\circ}$, Ley $N^{\circ}$ 20.600, de 2012.

35 Art. 13, Ley No 20.600, de 2012.

36 Así, por ejemplo, se ha encontrado justificación en algunas finalidades tales como la eficiencia, la priorización de los conflictos ambientales, la disminución del activismo general, entre otras. PRING y PRING (2009), pp. 14-16. Otros, en tanto, han señalado que uno de los caracteres fundamentales de un tribunal ambiental es su especialización a través de jueces que cuenten con conocimiento técnico ambiental en forma previa a su nombramiento. PrestOn (2014), p. 377.

37 Boettiger (2015), p. 228, quien plantea que nuestra comunidad jurídica no estaba suficientemente preparada para ofrecer una cantidad idónea de postulantes que cumplieran los estrictos requisitos técnicos previstos por la Ley $N^{\circ}$ 20.600. Aunque, me parece, para hacer una afirmación de ese tipo se requiere al menos de estudios empíricos que no solo analicen la cultura jurídico-ambiental chilena, sino también un análisis cuantitativo y cualitativo de cómo los tribunales ambientales están resolviendo al día de hoy.

38 Biblioteca del Congreso Nacional de Chile, Historia de la Ley No 20.600, p. 15.

39 Así, se lee en el Mensaje del Ejecutivo que derivó en la Ley № 20.600 que "La razón de esta integración está en que las cuestiones ambientales se mueven en un espacio de conocimiento altamente especializado, pero también incierto, por lo cual no sólo es razonable que puedan resolver las discrepancias los jueces letrados, sino que también quienes no invisten tal calidad, pero que 


\subsection{3. ...y preferentemente no sujetos al control de las cortes generalistas}

El tercer elemento depende de la relación que tenga el tribunal con las cortes generalistas ${ }^{40}$. Se trata de establecer si el tribunal "suplanta" la función revisora de los tribunales generalistas (i.e., Cortes de Apelaciones) o bien se encuentra subordinado completamente a dichos tribunales. En pocas palabras, ello depende de si la sentencia definitiva dictada por el tribunal será susceptible de revisión por las Cortes de Apelaciones o, por el contrario, únicamente ante la Corte Suprema.

En el sistema de la Ley $\mathrm{N}^{\circ} 20.600$, son los tribunales ambientales quienes realizarán la revisión de los actos dictados por la administración ambiental. Así, los tribunales superiores de justicia (i.e., Cortes de Apelaciones y la Corte Suprema) se mantienen un tanto al margen de dicho modelo. Ello queda de manifiesto con dos características básicas del modelo recursivo establecido en la Ley ${ }^{41}$.

En primer lugar, el régimen recursivo cuenta con una baja intensidad impugnativa. No todas las resoluciones dictadas por los tribunales ambientales son impugnables por vía de recurso ante los tribunales de justicia. Así, aunque el recurso de apelación no desaparece completamente, su ámbito de aplicación se restringe, estando acotado solo a dos clases de resoluciones dictadas durante el procedimiento de reclamación, i.e., las que declaren la inadmisibilidad de la reclamación y las que pongan término al proceso o hagan imposible su continuación ${ }^{42}$. Lo que hace la Ley $N^{\circ} 20.600$ es atenuar el control vertical en la sentencia definitiva por una mayor intensidad en el control horizontal, que está dado por el número de ministros (tres) que integran cada tribunal ambiental ${ }^{43}$.

En segundo término, y ligado a lo anterior, el régimen se caracteriza por una inexistencia de la doble instancia como mecanismo de impugnación de la sentencia definitiva. Dicha resolución es únicamente impugnable por vía

\footnotetext{
disponen de otra especialización que contribuye a una razonable y acabada decisión de los asuntos ambientales". Bibloteca del Congreso Nacional de Chile, Historia de la Ley No 20.600, p. 11.

40 Revesz (1990), p. 1133.

${ }^{41}$ Estas características ya las he explicado anteriormente. Al respecto, MéNDEZ (2017), pp. 189-190.

${ }^{42}$ Art. 26, inc. $1^{\circ}$, Ley No 20.600, de 2012.

${ }^{43}$ Esto ya lo habíamos evidenciado en nuestro país en materia procesal penal. Al respecto, HoRvitz y LóPEZ (2004), p. 353. Por lo demás, valga recordar que ya Tavolari predecía hace más de veinte años atrás que la organización de tribunales colegiados se incrementaría en nuestro país, disminuyendo con ello la importancia de la apelación como recurso obligatorio y por excelencia de la sentencia definitiva. TAVOLARI (1994), p. 65.
} 
de casación en la forma y en el fondo ${ }^{44}$. La especialización de los tribunales ambientales encuentra como correlato una restricción de las facultades revisoras de la Corte Suprema respecto de los tribunales ambientales. No guarda lógica el permitirles a las cortes superiores de justicia (generalistas) el conocimiento de materias de hecho y altamente técnicas (como las ambientales). Lo racional, tal como ha sido planteado en nuestro medio, es dejarles a éstas únicamente el conocimiento de infracciones de derecho por la vía de recursos especiales y de derecho estricto ${ }^{45}$.

\section{2. ¿El nuevo procedimiento contencioso ambiental? Poco ha cambiado}

Como se mencionó, hasta antes de la Ley No 20.600, los terceros opositores a proyectos de inversión utilizaron el recurso de protección como el mecanismo de impugnación por excelencia en contra de resoluciones de calificación ambiental ${ }^{46}$. Ello fue altamente criticado por la doctrina nacional. Sin embargo, nadie planteó la posibilidad de que los problemáticos resultados que se venían observando como consecuencia de la utilización del recurso de protección en materias ambientales, no se debían a una falta de preparación de las cortes generalistas, sino, en realidad, a las precarias reglas de procedimiento establecidas para el conocimiento de estas acciones constitucionales.

La prueba de lo anterior es que, pese a los problemas detectados en la Sección 1.1, no hubo una real sustitución del procedimiento con la Ley $N^{\circ}$ 20.600. Como consecuencia, la Ley No 20.600 consagró en un contenciosoadministrativo un procedimiento sumarísimo idéntico al procedimiento del recurso de protección. Así, una vez declarada admisible la reclamación, el tribunal ambiental procede a requerir informe al órgano público que dictó el acto administrativo impugnado ${ }^{47}$. Tras ello tiene lugar la vista de la causa, la

\footnotetext{
${ }^{44}$ Art. 26, incs. $3^{\circ}$ y $4^{\circ}$, Ley $N^{\circ} 20.600$, de 2012. En un inicio, el Mensaje del Ejecutivo ingresado a tramitación constitucional proponía un recurso de reclamación ante la Corte Suprema similar al existente en la actualidad en materia de libre competencia. Luego, en Primer Trámite Constitucional (Senado) se planteó una apelación en su lugar. En Segundo Trámite (Cámara de Diputados) finalmente se optó por seguir un clásico modelo de recurso de casación como el del Código de Procedimiento Civil, pero limitando sus causales a algunas de las contenidas en el artículo 768 del Código.

${ }^{45}$ Tapia y Cordero (2015), p. 57. Sin embargo, ello no siempre es así. Al respecto, Revesz (1990), pp. 1133-1135 con una descripción en el Derecho norteamericano.

46 Una exposición del panorama del recurso de protección como mecanismo de impugnación durante los primeros años en GALINDO (2001). Por su parte, un examen del período hasta antes de la entrada en vigencia de la Ley № 20.600, de 2012 y los tribunales ambientales en CORDERO (2012).
}

${ }^{47}$ Art. 29, inc. 20, Ley $N^{\circ} 20.600$, de 2012. 
que se ajusta a las reglas para el conocimiento y fallo del recurso de apelación civil. Concluida la vista, quedará cerrado el debate y el proceso en estado de dictarse sentencia ${ }^{48}$. La sentencia deberá ser dictada dentro de los 30 días siguientes a la vista de la causa ${ }^{49}$.

Resulta paradójico que, cuando toda la doctrina criticaba el recurso de protección como contencioso-administrativo, el Congreso haya optado por replicar las reglas procesales en cuestión. Así, por ejemplo, Pierry hace más de veinticinco años atrás ya señalaba respecto del procedimiento de protección que es "un procedimiento inadecuado, que no ofrece garantías procesales ni a la autoridad recurrida, ni a los terceros interesados en la mantención del acto, ni tampoco al propio recurrente, que no tiene criterios estables o permanentes en qué fundar su acción ${ }^{\prime 50}$. Pese al tiempo que ha pasado desde esta crítica, ella es aplicable a plenitud al contencioso-administrativo regulado en la Ley $\mathrm{N}^{\circ} 20.600$.

Lo anterior es por completo relevante. Las reglas de procedimiento afectan la manera en que los jueces se imponen de los asuntos sometidos a su conocimiento y, en consecuencia, en su forma de resolver. Por lo mismo, tal vez la forma en que las cortes generalistas estaban resolviendo los recursos de protección ambientales no se debía a su aludida falta de preparación técnica -como algunos sostuvieron-, sino a las notorias deficiencias de las reglas procesales utilizadas en el procedimiento de protección ${ }^{51}$.

Con todo, estas reglas de procedimiento, según se demostrará a continuación, generan dos consecuencias negativas: una que afecta a las partes procesales y otra que afecta al tribunal.

\footnotetext{
48 Art. 29, inc. $4^{\circ}$, Ley No 20.600, de 2012.

49 Más de alguien, incluso, podría sostener que en atención a ello las sentencias dictadas por los tribunales ambientales solo podrían alcanzar cosa juzgada formal, aplicando por analogía la opinión más reciente a propósito de la sentencia dictada en los procesos de protección. En efecto, la doctrina ha señalado que, en base a las características del procedimiento de protección, la sentencia que allí se dicte solo alcanza cosa juzgada formal (p. ej., PAIllás (1997), p. 90; Romero (2002), pp. 133 y ss.; FerRADA y otros (2003), p. 75). Dado que el procedimiento de reclamación es idéntico al de protección, pues, alguien podría pensar que la misma conclusión se aplica a la sentencia dictada por el tribunal ambiental. Pero ello, por cierto, amerita una discusión más profunda que la que permiten estas líneas.

50 Pierry (1991), p. 159. Véase, además, las citas a las notas 20 y 21.

51 No hay en Chile un estudio que se pronuncie sobre este tema. Tampoco es mi intención ofrecer una conclusión en este trabajo. De hecho, tal conclusión ameritaría un estudio empírico que com-

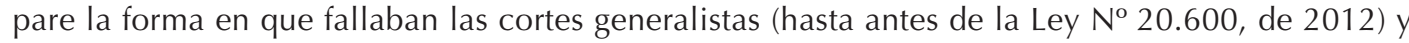
los nuevos tribunales ambientales. Un trabajo de este tipo, desde luego, excede al de estas líneas.
} 


\section{Primera consecuencia: carencia de un contradictorio adecuado entre partes}

En el procedimiento de reclamación hay una carencia de un contradictorio adecuado entre las partes, cuestión que se evidencia a través de dos circunstancias que se expondrán a continuación. Esto es altamente relevante, pues es a través de los escritos evacuados por las partes durante la etapa de discusión donde el juez tiene la posibilidad de imponerse de los hechos del juicio. Cualquier limitación, entonces, sobre la participación de las partes, necesariamente podría repercutir en la posibilidad que tiene el juez para conocer en forma adecuada de los hechos que motivan el juicio.

\subsection{Imposibilidad (al menos nominal) para oponer alegaciones, defensas o excepciones}

Como se dijo más arriba, tras la declaración de admisibilidad, el tribunal ambiental procederá a requerir de informe al organismo público reclamado ${ }^{52}$. No tiene lugar en el juicio de reclamación una especie de contestación de la demanda, como opera en la generalidad de los juicios declarativos en nuestro sistema legal. Esta regulación peculiar de la Ley $N^{\circ} 20.600$ genera dos dificultades prácticas.

Primero, la regulación del debate le impide al reclamado denunciar adecuadamente vicios procesales -tales como la falta de personería, la litis pendencia o la incompetencia del tribunal- antes de entrar a discutir sobre el fondo. La Ley $\mathrm{N}^{\circ} 20.600$ no solo carece de norma alguna en que regulen las excepciones dilatorias en este procedimiento, sino que ella además opera sobre una lógica que restringe al reclamado a evacuar un informe "que se limitará a consignar los fundamentos y motivos en los que el acto administrativo se basa" ${ }^{\prime \prime 3}$. En adición, los incidentes se tramitan en cuerdas separadas y se resuelven en la sentencia definitiva ${ }^{54}$. Así las cosas, la Ley $N^{\circ} 20.600$ hace derechamente inoficioso denunciar vicios procesales en forma previa a la discusión sobre el fondo del asunto controvertido. El organismo reclamado deberá oponer, si lo estima conveniente, las excepciones procesales del caso al evacuar su informe en la especie ${ }^{55}$.

\footnotetext{
52 Art. 29, inc. 20, Ley No 20.600, de 2012.

53 Art. 29, Ley No 20.600, de 2012.

54 Art. 23, Ley No 20.600, de 2012.

55 Esta idea, pese a ser bastante peculiar, es recogida también en nuestro ordenamiento en otros procedimientos como el juicio sumario (art. 690, Código de Procedimiento Civil).
} 
El grave demérito de esta regulación es que le resta relevancia a la depuración de los vicios procesales dentro del procedimiento de reclamación. Como es sabido, la idea fundamental dentro de todo proceso judicial es que los vicios de esta clase sean eliminados antes de discutir el fondo del asunto, pues podrían entorpecer a futuro el desarrollo del juicio. Ello es lo que explica la regla procesal por antonomasia en todo procedimiento, sea que estas excepciones sean opuestas y resueltas en forma previa a toda otra cuestión relativa al fondo del asunto, con el fin de economizar esfuerzos inútiles ${ }^{56}$.

En segundo lugar, la misma Ley pareciera impedirle al órgano administrativo incorporar alegaciones o defensas en su contestación. Como podrá comprenderse, limitarse a "consignar fundamentos y motivos" importa un estándar de discusión bastante menor al de oponer "alegaciones, defensas o excepciones", frente a la reclamación que da origen al proceso judicial. De ser aplicada en forma estricta, la regulación de la Ley No 20.600 es insuficiente para discutir a cabalidad todos los vicios de que puede adolecer un acto administrativo, los aspectos técnicos que rodean a su dictación, las posibilidades que hay para que el mismo pueda ser convalidado, o el perjuicio que legitima a los reclamantes para accionar, entre otros.

\subsection{Inexistencia de mecanismos de protección de terceros a los que pudiere afectar el contenido de la sentencia}

Desde hace tiempo la doctrina procesal ha venido entendiendo que las sentencias jurisdiccionales pueden, en la práctica, desplegar sus efectos sobre terceros ajenos al juicio en que ella haya sido pronunciada ${ }^{57}$. Así comenzó a hablarse de efectos directos y reflejos de la sentencia. Los primeros son aquellos que son queridos y previstos en la decisión judicial, perseguidos por las partes al promover el proceso; y pueden ser constitutivos, declarativos o de condena, según la pretensión deducida en juicio. Los segundos, en contraste, son aquellos referidos a terceros y que no son queridos ni previstos por el juez en la resolución, ni perseguidos directamente por las partes. Su causa inmediata se encuentra en la conexión de las relaciones materiales de los terceros con aquella que se ha ventilado en el juicio ${ }^{58}$.

\footnotetext{
${ }^{56}$ Couture (2014), p. 94. Por su parte, Benavente pone la atención en el contexto del juicio ordinario que " [I]a oposición de una excepción dilatoria trae como consecuencia el retardo de la entrada al juicio, ya que mediante ella el demandado pide al tribunal que declare que no está obligado a contestar la demanda mientras no se subsane el vicio que adolece". Benavente (2002), p. 23.

57 LieBMAN (1946).

58 Rosende (2001), pp. 489-507; Ortells (2002), pp. 476 y ss.
} 
Uno de los puntos no resueltos por la Ley № 20.600 es que ella carece de mecanismos de protección de terceros que, no siendo partes directas en el proceso de reclamación, pudiere afectar directamente el contenido de la sentencia dictada por el tribunal ambiental. Es bastante frecuente que las reclamaciones sean utilizadas por personas con el fin de impugnar un acto administrativo dictado por la administración ambiental que produce directamente consecuencias jurídicas en (i.e. efectos previstos e inmediatos en el patrimonio de una tercera persona). Así, por ejemplo, es posible que personas que formularon observaciones al Estudio de Impacto Ambiental estimen que la resolución del Comité de Ministros, calificando favorablemente el proyecto evaluado mediante dicho Estudio, no se ajusta a la ley y acto seguido reclamen en contra de dicha resolución al tribunal. El mismo caso podría presentarse cuando una persona, en virtud de cuya denuncia la Superintendencia tramita un proceso sancionatorio en contra del titular de un proyecto, estime que la resolución sancionatoria dictada contra aquel no se ajusta a la ley y decide reclamar.

En ambos ejemplos las partes directas del proceso de reclamación serán el reclamante y el organismo reclamado. En los dos casos, como se puede apreciar, el titular del proyecto será alcanzado en forma directa por los efectos de la sentencia que dicte el tribunal ambiental. En estas situaciones, pues, la sentencia extenderá sus efectos sobre el titular, un tercero que no ha comparecido en el juicio y que no ha tenido la oportunidad para formular alegaciones o defensas frente a la reclamación.

Esta clase de problemas no ha sido abordada por la Ley № 20.600. En el corto tiempo que ha mediado desde su implementación a la fecha, tampoco los tribunales ambientales nacionales han generado mecanismos jurisprudenciales que permitan a estos terceros actuar a través de una intervención voluntaria o forzada ${ }^{59}$. Ni siquiera han tendido a notificar a estos terceros de la existencia del proceso pendiente. En la práctica, la comparecencia de estos terceros se ha dado a raíz de una comparecencia, motu proprio, como terceros coadyuvantes en los respectivos procesos con el fin de defender sus derechos e intereses ${ }^{60}$.

\footnotetext{
59 FerRada (2015), p. 311. Pronunciándose sobre la necesidad de proteger a terceros en procesos civiles, Romero señala que en la intervención voluntaria "el tercero legitimado concurre libremente al proceso en curso para defender sus derechos o intereses; en la intervención provocada, en cambio, el tercero ingresa al juicio, a petición de parte o por orden del juez, bajo la amenaza de producirse en su contra algún efecto jurídico si no comparece a dicho proceso". ROMERo (2014), p. 192.

60 A propósito de la intervención de terceros, el art. 18, inc. $2^{\circ}$ de la Ley № 20.600, de 2012, hace aplicable en el contencioso-administrativo lo establecido en el art. 23 del Código de Procedimiento Civil.
} 


\section{Segunda consecuencia: limitaciones a las facultades revisoras de los tribunales ambientales}

Un aspecto íntimamente ligado a la especialización del tribunal dice relación con sus facultades revisoras. Desde un punto de vista regulatorio, lo lógico es que un tribunal especializado cuente con facultades amplias de revisión, pues sus conocimientos y la justificación detrás de su creación le permiten examinar con confianza no solo cuestiones de derecho, sino también de hecho y de políticas públicas ${ }^{61}$.

Sin embargo, pese al alto grado de especialización con que cuentan los tribunales ambientales -ya expuesto en la Sección 2.1-, las normas procesales de la Ley $N^{\circ} 20.600$ imponen ciertos límites sobre las facultades revisoras con que cuentan los tribunales ambientales respecto de los actos administrativos ante ellos impugnados. Esto, en último término, resulta contradictorio con el carácter especializado que detentan dichos tribunales.

\subsection{El juez ambiental solo revisa el expediente administrativo del cual emana el acto impugnado}

En materia contencioso-administrativa, la revisión del acto de la administración por parte del juez puede ser, según la forma en que se desenvuelve en el procedimiento, de novo o tras una mera revisión del expediente administrativo $^{62}$. En el primer caso el tribunal realiza una completa revisión del acto administrativo impugnado y, por lo mismo, todos los Medios probatorios son admisibles. Básicamente la idea es que aquí se está frente a un contradictorio completo en que el juez reconstruye todos los hechos que han motivado la dictación del acto de la Administración, con total independencia de las conclusiones a las que haya podido arribar la autoridad administrativa ${ }^{63}$. Resulta común que este modelo de revisión sea utilizado en aquellos casos en que el tribunal cuenta con un alto grado de especialización, cuestión que le permite revisar con confianza todos los aspectos que rodean a la dictación del acto administrativo impugnado. Como consecuencia, la instauración de procedimientos de revisión de novo deriva generalmente en una falta de deferencia frente a la administración tanto en los hechos como en el derecho ${ }^{64}$.

\footnotetext{
61 TAPIA Y CORDERO (2015).

62 Sobre esto, Hunter (2015), pp. 651-653; Currie y GoOdman (1975), y MerriLl (2011), con referencias al derecho norteamericano.

63 Merrill (2011), pp. 946-953, señalando que esta fue la forma de revisión por excelencia en el Derecho norteamericano durante el siglo XIX.

${ }^{64}$ MerRill (2011), p. 952.
} 
En el segundo tipo de revisión, en contraste, el tribunal únicamente revisa la totalidad del expediente administrativo que ha dado origen al acto revisado. Por lo mismo, las pruebas se encuentran limitadas en el proceso judicial impugnatorio, siendo el expediente la principal prueba. La idea es que un nuevo juicio no es necesario porque el órgano administrativo ya ha recopilado todos los hechos que fundamentan su decisión; por consiguiente, la construcción de un nuevo expediente no es necesaria porque ya ha sido elaborado en sede administrativa ${ }^{65}$. En muchos casos, este modelo se opta cuando son las cortes generalistas las encargadas de la revisión judicial de los actos administrativos y, como consecuencia de ello, el órgano administrativo cuenta con mejores y mayores posibilidades de recopilar adecuadamente los hechos y generar un buen expediente ${ }^{66}$.

Los tribunales ambientales operan en base a un modelo de mera revisión de la actividad administrativa ${ }^{67}$. No realizan una revisión de novo construyendo un nuevo expediente para este fin. Bajo la regulación de la Ley $N^{0} 20.600$, lo normal es que, dentro del procedimiento de reclamación, el juez ambiental termine revisando y valorando únicamente el expediente administrativo del cual emana el acto impugnado.

La Ley $N^{\circ} 20.600$, tal como fue señalado, obliga al organismo reclamado a acompañar copia autenticada "del expediente administrativo completo y debidamente foliado que sirvió de base para dictar el acto administrativo que se impugna"68. En adición, la Ley señala en términos expresos que la tramitación de la reclamación seguirá las reglas de conocimiento y fallo de la apelación civil, con la salvedad de que "no se admitirán prueba testimonial ni confesional"69. Como es sabido, en materia de apelación no se admite prueba alguna por regla general ${ }^{70}$. Por lo mismo, debe entenderse que en las acciones de reclamación no será admisible ningún medio probatorio, con la única

\footnotetext{
${ }^{65}$ Currie y Goodman (1975), p. 5.

66 MerRiLl (2011).

${ }^{67}$ En el mismo sentido, Hunter (2015), pp. 651-652 y, recientemente Bordalí y Hunter (2017), pp. 243-246.

${ }^{68}$ Art. 29, inc. $3^{\circ}$, Ley $\mathrm{N}^{0} 20.600$ de 2012. Nótese que no se trata de una inversión de la carga de la prueba, sino de la imposición de un deber de colaboración entre las partes del juicio. Este deber es una forma especial de exhibición documental que busca facilitar la labor probatoria que, en principio, debería soportar el actor por sí solo. HunTER (2015), p. 655. Para ello, presupone el cumplimiento de la obligación que deben observar los órganos administrativos de dictar actos en base a un expediente debidamente foliado, según las reglas de la Ley de Procedimientos Administrativos. Arts. $5^{\circ}$ y 18, Ley No 19.880, de 2003. En este sentido, FerRADA (2015b), pp. 313-314.

${ }^{69}$ Art. 29, inc. 30, Ley No 20.600, de 2012.

70 Art. 207, Código de Procedimiento Civil.
} 
excepción de la prueba documental, la que podrá ser acompañada hasta antes de la vista de la causa ${ }^{71}$. Solo excepcionalmente se permitirá la producción de prueba nueva o adicional por vía de las medidas para mejor resolver ${ }^{72}$. En suma, prácticamente la única prueba que tendrá el tribunal ambiental será el expediente administrativo aportado por el organismo reclamado.

Esta restricción probatoria confirma el hecho de que los tribunales ambientales operan en base a un modelo de mera revisión de la actividad administrativa. Así, los hechos relevantes quedarán en su mayor parte probados en sede administrativa, solo siendo relevante la admisión de prueba en casos puntuales, tales como cuando la Administración haya omitido o denegado algún medio probatorio o cuando se trate de probar hechos que no constan en el expediente. La ventaja de este modelo de revisión, como se dijo, es su eficiencia. Este modelo parte de la idea de que una revisión de novo es innecesaria, porque la función de recopilación de hechos ya ha sido desarrollada por la Administración. En consecuencia, el procedimiento judicial será más breve, aliviando la carga de las partes y del tribunal ${ }^{73}$.

Sin embargo, resulta por completo cuestionable la decisión legislativa de restringir tan notoriamente la prueba en el juicio de reclamación. ¿Cómo podría ser justificable, por ejemplo, que las partes ni siquiera puedan proponer la declaración de testigos expertos o la inspección personal del tribunal? Como nos recuerda Taruffo, "el derecho a presentar todas las pruebas relevantes es parte esencial de las garantías generales sobre la protección judicial de los derechos y del derecho a defensa, pues la oportunidad de probar los hechos que apoyan las pretensiones de las partes es condición de tales garantías ${ }^{\prime 74}$. En consecuencia, la instauración de reglas de exclusión de pruebas por el legislador debe encontrar su fundamento en valores e intereses judiciales o extrajudiciales realmente importantes, como evitar dilaciones o perjuicios, o evitar errores o malentendidos de parte del juzgador ${ }^{75}$. Ninguna de dichas razones, con todo, se aprecian aquí.

\footnotetext{
71 Arts. 207 y 348, Código de Procedimiento Civil.

72 Art. 29, inc. 4', Ley No 20.600, de 2012.

73 Currie y Goodman (1975), pp. 5-6.

${ }^{74}$ Taruffo (2008), p. 56. Por su parte, Bordalí y Ferrada (2008), p. 185, han señalado que dentro de las ideas fundantes de todo contencioso-administrativo es que en el mismo "se permita la presentación de cualquier medio probatorio tanto por las partes como por el juez".

75 TARufFo (2008), p. 57, en especial, pp. 41-56, con un análisis de casos legislativos en los sistemas de civil y common law sobre exclusión y privilegios probatorios.
} 


\subsection{El juez solo realiza una revisión de legalidad del acto, sin poder dictar en ningún caso un acto de reemplazo}

Según su alcance o estándar, la revisión que ejerce un tribunal sobre los actos de la Administración del Estado puede ser de legalidad (o "estricta") o de mérito (también llamada de "jurisdicción plena"). En la primera, el órgano revisor solo puede controlar la forma en que la decisión administrativa ha sido adoptada, orientándose en la "legalidad", la "irracionalidad" o "arbitrariedad" o la "impropiedad procedimental" de la actuación administrativa. El segundo tipo de revisión, en cambio, es más amplio, estando el tribunal incluso facultado para analizar lo correcto o incorrecto de la decisión adoptada por el órgano ${ }^{76}$.

Los tribunales ambientales no realizan una revisión plena o de mérito u oportunidad, sino que su labor se encuentra acotada a los eventuales vicios de nulidad de que pueda adolecer el acto impugnado. Así, la Ley № 20.600 señala que la sentencia que acoja la acción "deberá declarar que el acto no es conforme a la normativa vigente y, en su caso, anulará total o parcialmente la disposición o el acto recurrido"77. Como consecuencia de ello, el tribunal no puede "determinar el contenido discrecional de los actos anulados", pudiendo solo disponer "que se modifique, cuando corresponda, la actuación impugnada"78. Esto, como lo han señalado algunos, importa una limitación normal a la justicia administrativa recogida desde la legislación española sobre la materia ${ }^{79}$. La idea que hay detrás de la Ley $N^{\circ} 20.600$ es que "II]os tribunales administrativos son jueces de administración, pero no administran", manteniendo el principio de separación de poderes en este ámbito ${ }^{80}$.

Este modelo genera una incoherencia si es comparado con el modelo anterior al 2012. Como se señaló más arriba, antes de la Ley No 20.600, los actos administrativos sancionatorios dictados por la autoridad ambiental de la época (las Coremas y la Conama) eran impugnables ante la justicia ordinaria. El juez con competencia en lo civil, en ese entonces, contaba incluso con facultades para mantener, modificar o revocar la sanción impuesta por la administración. Este régimen fue alterado drásticamente con la implementación de los tribunales ambientales. Y estos, de acuerdo a la Ley $N^{\circ} 20.600$,

\footnotetext{
76 TAPIA y CoRdero (2015), p. 35.

77 Art. 30, inc. 1 ${ }^{\circ}$, Ley No 20.600, de 2012.

${ }^{78}$ Art. 30, inc. 2 , Ley No 20.600, de 2012.

79 Ferrada (2015), p. 321.

${ }^{80}$ Valdivia (2015), p. 268.
} 
no cuentan al día de hoy con facultades para dictar un acto administrativo de reemplazo.

A mayor abundamiento, nuestros tribunales han entendido en forma tácita que la imposición de sanciones por parte de la SMA constituye un acto de contenido discrecional y, por tanto, sujeta a la restricción del artículo 30, inciso $2^{\circ}$ de la Ley $N^{\circ} 20.600$. Ello ha llevado a que los tribunales ambientales, en caso de sentencias favorables al actor, se limiten a anular la resolución sancionatoria e impartan órdenes directas a la Superintendencia del Medio Ambiente tales como enmendar sus resoluciones sancionatorias con el fin de subsanar los vicios que derivaron en la nulidad del acto impugnado ${ }^{81}$, o a retrotraer procedimientos sancionatorios ${ }^{82}$ o de fiscalización ${ }^{83}$. No deja de ser paradójico que antes, los tribunales generalistas tuvieran facultades parar modificar las sanciones impuestas por la administración y ahora, los tribunales especializados carezcan de las mismas.

\section{Conclusiones}

Una de las razones institucionales que motivaron el nacimiento de tribunales ambientales en nuestro país fue que en muchos sectores existía la sensación de que las cortes generalistas no estaban resolviendo adecuadamente los casos (contencioso-administrativo) ambientales. Como es sabido, hasta el año 2012 la acción constitucional de protección fue el mecanismo de impugnación por excelencia de actos administrativos de contenido ambiental en nuestro país, i.e., resoluciones de calificación ambiental emitidas por la autoridad administrativa. Durante esta época se dijo que las cortes no estaban resolviendo adecuadamente estos casos bien porque desconocían el Derecho Ambiental o porque no estaban preparadas para resolver asuntos altamente técnicos. Gran parte de la doctrina nacional también criticó el uso de esta acción constitucional en este ámbito, principalmente por su carácter simplista y desformalizado, que le impiden al juez conocer temas técnicamente complejos, como es el caso de los temas ambientales.

Pese a ello, nadie en nuestro medio hizo la conexión entre ambas críticas. Nadie planteó la posibilidad de que el problema en cuestión se debía no a una falta de preparación de las cortes generalistas, sino en realidad a las precarias reglas de procedimiento establecidas para el conocimiento de acciones constitucionales de protección. Prueba de ello fueron las reglas

\footnotetext{
${ }^{81}$ Segundo Tribunal Ambiental, rol No R-26-2014, de 17 de diciembre de 2014.

${ }^{82}$ Segundo Tribunal Ambiental, rol № R-33-2014, de 30 de julio de 2015.

${ }^{83}$ Segundo Tribunal Ambiental, rol No R-20-2014, de 19 de junio de 2014.
} 
procedimentales establecidas en la Ley № 20.600 de 2012. Esta ley (i) creó una serie de tribunales ambientales como tribunales especiales de competencia exclusiva y excluyente para la revisión de actos administrativos, conformados por miembros especialistas y no sujetos preferentemente a las cortes generalistas de nuestro país (i.e., las Cortes de Apelaciones) y; (ii) consagró un contencioso-administrativo con reglas virtualmente idénticas al recurso de protección.

Tal como se ha señalado en el cuerpo de este artículo, dichas reglas de procedimiento son inadecuadas y altamente ineficientes como contenciosoadministrativo en materia ambiental. Al igual que lo que ocurría en materia de acción de protección, ellas, en primer lugar, consagran una tramitación sumarísima que genera diversas complicaciones prácticas. Así, por ejemplo, este procedimiento carece de un contradictorio adecuado entre las partes, impide la depuración de vicios procesales antes de entrar a conocer el fondo del asunto, opera sobre la idea de que el órgano revisor realiza una mera revisión del expediente administrativo y restringe los Medios probatorios drásticamente.

En segundo lugar, dichas reglas son incongruentes con la forma en que los tribunales ambientales ejercen sus facultades revisoras. Pese a que los tribunales ambientales cuentan con altos incentivos para no guardar deferencia con las decisiones adoptadas por la Administración ambiental y para ejercer una revisión amplia -congruente con su propia naturaleza, especialización técnica y los motivos históricos que fundamentaron su implementación en nuestro país-, dichas reglas operan como obstáculos en el ejercicio de la función revisora por parte de los tribunales ambientales.

Así las cosas, los tribunales ambientales son tribunales administrativos especiales que se encuentran atrapados en un procedimiento contenciosoadministrativo de revisión limitada. En otras palabras, todas las limitaciones procesales expuestas en este trabajo, en definitiva tienen la potencialidad de funcionar como trabas institucionales para que los tribunales ambientales puedan administrar adecuadamente justicia al conocer de las controversias medioambientales ventiladas ante ellos. Y esto no es una cuestión de menor gravedad. Si vamos a crear tribunales administrativos especiales, lo menos que podemos hacer como sociedad es asegurarnos de garantizar reglas procesales que no solo salvaguarden los derechos de los sujetos administrados, sino que también les permitan a los tribunales ejercer su función de manera efectiva y eficiente. Todo lo demás, es desperdicio de recursos públicos.

\section{BIBLIOGRAFÍA CITADA}

Benavente, Darío (2002): Derecho procesal civil. Juicio ordinario y recursos procesales (Chile, Editorial Jurídica de Chile, 5ª edición). 
Bermúdez, Jorge (2011): Derecho administrativo general, 2ª edición (Chile, Legal Publishing).

(2014): Fundamentos de derecho ambiental, $2^{\mathrm{a}}$ edición (Chile, Ediciones Universitarias de Valparaíso).

Boettiger, Camila (2010): "Nueva Institucionalidad Ambiental", en Revista Actualidad Jurídica de la Universidad del Desarrollo ( $\left.N^{\circ} 22\right)$, pp. 429-454.

(2015): "Instalación de los tribunales ambientales: ¿problemas de diseño?", en: Revista Actualidad Jurídica Universidad del Desarrollo ( $N^{\circ} 31$ ), pp. 223-234.

Bordalí, Andrés y Ferrada, Juan Carlos (2008): Estudios de Justicia Administrativa (Chile, LexisNexis).

Bordalí, Andrés y Hunter, Iván (2017): Contencioso Administrativo Ambiental (Chile, Editorial Librotecnia).

Casarino, Mario (2014): Manual de Derecho Procesal Civil, reimpresión de la $6^{a}$ edición (Chile, Editorial Jurídica de Chile) Tomo I.

CANE, Peter (2009): Administrative tribunals and adjudication (Estados Unidos, Hart Publishing).

Centro de Derecho Ambiental (2012): "Los Tribunales Ambientales y la Superintendencia del Medio Ambiente. Una relación ineludible", en: Montenegro, Sergio y otros (coords.), Actas de las VI Jornadas de Derecho Ambiental (Chile, Abeledo Perrot), pp. 521-548.

Cordero, Luis (2012): "Corte Suprema y Medio Ambiente. ¿Por qué la Corte está revolucionando la regulación ambiental?", en: Couso, Jorge (edit.), Anuario de Derecho Público (Chile, Ediciones Universidad Diego Portales), pp. 359-375.

Couture, Eduardo (2014): Fundamentos de Derecho procesal civil, $5^{\mathrm{a}}$ reimpresión de la $4^{\mathrm{a}}$ edición (Argentina, Edit. B de F).

Currie, David y GoOdman, Frank (1975): "Judicial review of federal administrative Action: quest for the optimum forum", en: Columbia Law Review (Vol. 71, $\mathrm{N}^{\mathrm{0}}$ 1), pp. 1-88.

FerradA, Juan Carlos (2015): "La justicia ambiental como justicia administrativa especializada y su articulación con los procesos administrativos generales", en: Ferrada, Juan Carlos; Bermúdez, Jorge y Pinilla, Francisco (coords.), La nueva justicia ambiental (Chile, Legal Publishing), pp. 299-328.

Ferrada, Juan Carlos; Bordalí, Andrés, y Cazor, Kamel (2003): “El recurso de protección como mecanismo de control jurisdiccional ordinario de los actos administrativos: Una respuesta inapropiada a un problema jurídico 
complejo", en: Revista de Derecho de la Universidad Austral (Vol. 14), pp. 67-81.

Fuller, Lon (1978): "The forms and the limits of adjudication", en: Harvard Law Review (Vol. 92), pp. 353-409.

Galindo, Mario (2001): El Sistema de Evaluación de Impacto Ambiental ante la Jurisprudencia: 1996-2000 (Chile, Comisión Nacional del Medio Ambiente).

(2006): “Diagnóstico y reforma de los procedimientos jurisdiccionales ambientales", en: Actas de las Terceras Jornadas de Derecho Ambiental (Chile, Facultad de Derecho de la Universidad de Chile), pp. 17-29.

Guiloff, Matías (2010): “Campiche: Es revisable la resolución de calificación ambiental", en: Couso, Jorge (edit.), Anuario de Derecho Público (Chile, Ediciones Universidad Diego Portales), pp. 204-219.

(2011): "Nueva Institucionalidad Ambiental: Hacia una regulación deliberativa", en: Couso, Jorge (edit.), Anuario de Derecho Público (Chile, Ediciones Universidad Diego Portales), pp. 231-242.

Hervé, Dominique; Guiloff, Matías, y Pérez, Raimundo (coords.) (2010): Reforma a la Institucionalidad Ambiental. Antecedentes y Fundamentos (Chile, Ediciones Universidad Diego Portales).

Horvitz, María Inés y LóPEZ, Julián (2004): Derecho procesal penal chileno (Chile, Edit. Jurídica de Chile), Tomo II

HUNTER, Iván (2015): "La carga de la prueba en el contencioso ambiental chileno: Notas a propósito de la ley de tribunales ambientales", en: Revista Chilena de Derecho (Vol. 42, № 2), pp. 649-669.

LIEBMAN, Enrico Tullio (1946): Eficacia y autoridad de la sentencia y otros estudios sobre la cosa juzgada (Argentina, Ediar).

MéndeZ, Pablo (2017): Tribunales Ambientales y Contencioso-Administrativo. El Procedimiento de Reclamación de la Ley N²0.600 (Chile, Editorial Jurídica de Chile).

MeRRILL, Thomas (2011): "Article III, agency adjudications, and the origins of the appellate review model of administrative law", en: Columbia Law Review (Vol. 111, No 5), pp. 939-1003.

ORGANIZACIÓN DE COOPERACIÓN Y DeSARROLlo ECONÓMICOS Y COMISIÓN ECONÓMICA PARA América Latina y El Caribe (2005): Evaluaciones del Desempeño Ambiental. Chile (Chile, Naciones Unidas-Cepal).

Ortells, Manuel (2002): Derecho procesal civil (España, Aranzadi, $3^{\text {a }}$ edición).

Pallzás, Enrique (1997): El recurso de protección ante el derecho comparado (Chile, Editorial Jurídica de Chile). 
Pierry, Pedro (1977): "El recurso de protección y lo contencioso administrativo", en: Revista de Derecho de la Universidad de Concepción ( ${ }^{\circ}$ 165), pp. 175-188.

(1991): "Conferencia inaugural. Lo contencioso administrativo y el recurso de protección", en: Revista de Derecho de la Universidad Católica de Valparaíso ( $\left.\mathrm{N}^{0} 14\right)$, pp. 155-171.

Poklepovic, Iván (2012): "Compatibilidad del recurso de protección ambiental con la competencia del Tribunal Ambiental en el contencioso administrativo del Sistema de Evaluación de Impacto Ambiental", en: Montenegro, Sergio y otros (coords.), Actas de las VI Jornadas de Derecho Ambiental (Chile, Abeledo Perrot), pp. 521-548.

PRESTON, Brian (2014): "Characteristics of successful environmental courts and tribunals", en: Journal of Environmental Law ( ${ }^{\circ}$ 26), pp. 365-393.

PrING, George y PRING, Catherine (2009): Greening justice: Creating and improving environmental courts and tribunals (Estados Unidos, The Access Initiative).

Revesz, Richard (1990): "Specialized courts and the administrative lawmaking system", University of Pennsylvania Law Review (Vol. 138), pp. 1111-1174.

Romero, Alejandro (2002): La cosa juzgada en el proceso civil (Chile, Edit. Jurídica de Chile).

(2014): Curso de derecho procesal civil, Tomo II (Chile, Legal Publishing, $2^{\mathrm{a}}$ edición).

Rosende, Cecilia (2001): "Efectos directos y reflejos de la sentencia", en: Revista Chilena de Derecho (Vol. 28, No 3), pp. 487-507.

TAPIA, Javier y CORDERO, Luis (2015): "La revisión judicial de las decisiones regulatorias: Una mirada institucional", en: Estudios Públicos (No 139), pp. 7-65.

TARuffo, Michelle (2008): La prueba (España, Marcial Pons).

Tavoları, Raúl (1994): "Hacia una teoría general de la impugnación", en: Tavolari, Raúl, Comentarios procesales (Chile, Ediciones Universitarias de Valparaíso), pp. 37-66.

Tribunal Ambiental de Santiago (2018): "Búsqueda de causas". Disponible en: http://consultas.tribunalambiental.cl/ambiental_portal/Web/Portal/LEX_ POR_ConsultaCausa.aspx. Fecha de consulta: 30 de junio de 2018.

Tribunal Ambiental de Valdivia (2018): "Sistema de gestión de causas". Disponible en: https://causas.3ta.cl/. Fecha de consulta: 30 de junio de 2018.

Tribunal Ambiental de Antofagasta (2018): "Sistema de gestión de causas". Disponible en: https://causas.1 ta.cl/. Fecha de consulta: 30 de junio de 2018. 
Valdivia, José Miguel (2015): "Contenido y efectos de las sentencias de los tribunales ambientales", en Ferrada, Juan Carlos; Bermúdez, Jorge y Pinilla, Francisco (coords.), La nueva justicia ambiental (Chile, Legal Publishing), pp. 225-276.

NORMA JURÍDICA CITADA

Código de Procedimiento Civil.

Ley $N^{\circ} 18.168$, Ley General de Telecomunicaciones. Diario Oficial, 2 de octubre de 1982 .

Ley No 18.838, Crea el Consejo Nacional de Televisión. Diario Oficial, 30 de septiembre de 1989.

Ley No 19.880, Establece Bases de los Procedimientos Administrativos que rigen los Actos de los Órganos de la Administración del Estado. Diario Oficial, 29 de mayo de 2003.

Ley $\mathrm{N}^{\circ}$ 19.886, Ley de bases sobre contratos administrativos de suministro y prestación de servicios. Diario Oficial, 30 de julio de 2003.

Ley N $N^{0}$ 19.911, Crea Tribunal de Defensa de la Libre Competencia. Diario Oficial, 14 de noviembre de 2003.

Ley $N^{0} 20.322$, Fortalece y perfecciona la justicia tributaria y aduanera. Diario Oficial, 27 de enero de 2009.

Ley $\mathrm{N}^{0}$ 20.473, Otorga, transitoriamente, las facultades fiscalizadoras y sancionadoras que indica a la Comisión señalada en el artículo 86 de la Ley No 19.300. Diario Oficial, 13 de noviembre de 2010.

Ley $N^{0}$ 20.600, Crea los Tribunales Ambientales. Diario Oficial, 28 de enero de 2012.

\section{JURISPRUDENCIA CITADA}

Arica Seafoods con SMA (2014): Segundo Tribunal Ambiental, 17 de diciembre de 2014 (reclamación), rol No R-26-2014.

Compañía Minera Maricunga con SMA (2014): Segundo Tribunal Ambiental, 19 de junio de 2014 (reclamación), rol Nº R-20-2014.

Comunidad Indígena Diaguita Yastai de Juntas de Valeriano y otros con Comisión de Evaluación Ambiental (2014): Corte Suprema, 7 de octubre de 2014 (apelación de recurso de protección), rol N 11299-2014.

Corporación Fiscalía del Medio Ambiente con Comisión de Evaluación Ambiental del Servicio de Evaluación Ambiental de la Región de Aysén 
(2014): Corte Suprema, 25 de agosto de 2014 (apelación de recurso de protección), rol № 8774-2014.

Correa, Ricardo con Comisión Regional del Medio Ambiente de Valparaíso (2010): Corte Suprema, 22 de junio de 2009 (apelación de recurso de protección), rol № 1219-2009.

Junta de Vecinos JJ.VV. Norte con Comisión de Evaluación Ambiental V Región (2014): Corte Suprema, 29 de abril de 2014 (apelación de recurso de protección), rol No 2892-2014.

Minera Los Pelambres con SMA (2015): Segundo Tribunal Ambiental, 30 de julio de 2015 (reclamación), rol No R-33-2014. 